discharge current due to the first charging. An experimental coil was then made up of $1,800 \mathrm{ohms}$ of wire having unparaffined cotton insulation. It was wound on a warm rainy day, and tested immediately, showing the strongest polarization found, driving the spot of light violently off the scale. The coil was then baked in a hot-air oven at $150^{\circ} \mathrm{C}$. for an hour, and tested again when cool. No trace of polarization could then be found, though the charging current was increased. The previous observations of course indicated electrolytic polarization as the disturbing cause; and the last showed, that, in the case of that coil, it was electrolysis of water absorbed from the air by the cotton insulation. The experimental coil was then heated, and soaked well with pure paraffine, and drained while hot until it seemed to be as nearly as possible in the same condition as the 40,000 Elliott coil, and tested when cool. No trace of polarization was shown. It was then put aside in the instrument case to see whether it could still absorb water enough to polarize. Ten days later, just after the Buffalo meeting, the coil was tested again and polarized strongly. On heating it again, the polarization entirely disappeared. A drop of hydrant water placed on the coil caused polarization to re-appear in five seconds, and in five minutes the effect was so strong as to drive the needle to its stops.

The degree of error in measurement resulting from polarization was not examined, but Professor Mendenhall's statements show that it may be a considerable quantity.

It is obvious that unparaffined coils are, on this account, unsuited to the best work; also that coils well paraffined (as in the B.A. unit coil) or coils freshly baked and paraftined are free from such error.

The paraffining of ordinary coils, even when as thoroughly done as by the Elliotts, is not a permanent protection, probably because of cracking of the mass of paraffine, allowing vapor to reach the wire and insulation. A test will quickly determine the condition of any particular coil. A box might be made proof against polarization by filling entirely the space about the freshly baked coils with pure paraffine, just warm enough to flow freely. Temperature difficulties could be in part overcome by thermojunctions, as in standards. Another and on some accounts better plan would be to mount the coils in an impervious box with liquid-tight joints, and filling the interior with a petroleum oil, which may readily be found in market, of such quality as to exhibit no polarization. With such a box, there need be no uncertainty as to the temperature of the coils.

Benj. F. Thomas.

Columbus, O., Dec. 27 .

\section{Atmospheric lines in the solar spectrum.}

The ingenious device recently published by $\mathbf{M r}$. Conner, for detecting the lines in the solar spectrum due to the earth's atmosphere, recalls a similar plan proposed by the writer some years ago. In a letter dated Feb. 21, 1883, I wrote to Professor Rowland, "I hope that you will try the experiment of which I spoke to you last summer, - forming two images of the sun, and photographing the spectra of the opposite limbs. A glance would serve to distinguish the solar from the telluric lines." An accompanying sketch showed that a double-image prism was to be placed between the slit and a lens forming an image of the sun upon it. This prism was to be moved until the two images were in contact. The east and west limbs were thus brought together, and the slit was placed at right angles to their line of junction. In the photograph, telluric lines should cross the spectrum undeviated, while solar lines would be bent in opposite directions where they crossed the line of separation of the two spectra. The advantages of this method over that of Mr. Conner are, first, its simplicity, as it is easily tried by any one who has a spectroscope giving a sufficient diffusion; secondly, the solar lines, instead of becoming hazy, continue well defined. For these reasons I call attention to the matter, and not to detract from the credit due to the eminent French physicist, who has preceded me both in trying and publishing a solution of this very important problem. EDward C. Pickering.

Harvard coll. observ., Jan. 1, 1887.

\section{A brilliant meteor.}

On Jan. 3, 1887, at 5.15 P.M., I observed a meteor of unusual brilliancy. It started, as nearly as I could make out, from the constellation Ursa Minor, possibly a little higher up, moving with a rapid rush and brilliant light in an easterly direction. As it neared the horizon, its speed apparently diminished, until it disappeared behind some trees. It was visible fully thirty seconds, and, during the last part of its flight, appeared to float slowly downwards. A trail of considerable length was drawn behind, giving it the appearance of a large rocket. Its flight was unattended by any sound. $\quad$ R. W. WooD, Jr.

Jamaica Plain, Mass.

\section{What was the rose of Sharon?}

I notice in your issue of Dec. 31 an article on the rose of Sharon. Without desiring to enter into the discussion of this subject, I wish to refer those interested to a few words upon this subject by an eminent investigator. Speaking of that part of the pleistocene plain near Jaffa, bordering the Mediterranean Sea, Sir J. W. Dawson, in his recent work on 'Egypt and Syria,' says, "In February we found it gay with the beautiful crimson anemone (A. coronaria), which we were quite willing to accept as the ' rose of Sharon,' while a little yellowish-white iris, of more modest appearance, growing along with it, represented the 'lily-of-the-valley' of Solomon's song." From this would it not be reasonable to infer that this anemone is quite generally recognized as the 'rose of Sharon'?

Brookville, Ind., Jan. 3, 1887.

\section{Electrical phenomena on a mountain.}

In confirmation of the observations of M. F. (Science, viii. p. 564) in relation to electrical phenomena on Lone Mountain, near Bozeman, I beg leave to call attention to the fact that more than twelve years ago Mr. Franklin Rhoda, assistant topographer, in his 'Report on the topography of the San Juan country' (vide F. V. Hayden's Report of U:S. geological and geographical survey of the territories for the year 1874, pp. 456-458, also p. 461), gives a detailed and graphic account of similar electrical manifestations experienced by Mr. A. D. Wilson and 
himself at station No. 12, on one of the peaks of the San Juan Mountains, in August, 1874, at an altitude of 13,967 feet above the level of the sea.

An interesting and significant circumstance recorded by Mr. Rhoda was the fact that there was a sudden and instantaneous cessation of the distressing electrical manifestations whenever a stroke of lightning took place, to be speedily renewed by the returning tension of the electricity. He says, "The sharp points of the hundred stones about us each emitted a continuous sound, while the instrument outsang every thing else, and, even at this high elevation, could be heard distinctly at the distance of fifty yards. The points of the angular stones being of different degrees of sharpness, each produced a sound peculiar to itself. The general effect of all was as if a heavy breeze were blowing across the mountain. The air was quite still, so that the wind could have played no part in this strange natural concert, nor was the intervention of a mythological Orpheus necessary to give to these trachytic stones a voice."

John Le Conte.

Berkeley, Cal., Dec. 25.

\section{Stereoscopic vision.}

In reply to the inquiry of Mr. W. H. Pratt in the last issue of Science, it is necessary only to consider the various elements which are combined in the formation of a visual judgment. If an observer, who possesses but a single eye, looks out upon a landscape, the relative distance of the different objects viewed may be roughly estimated in terms of some standard arbitrarily chosen, so long as they are not precisely aligned with his eye. The judgment is less accurate as the angular separation of the objects becomes less, and as there are fewer of them at moderate distances for comparison with the rest. Always, and usually unconsciously, he employs one or more of the following elements in judging the distance and form of each object regarded :-

I. Near objects subtend larger visual angles than remote objects of equal size.

II. Near objects are seen more distinctly than those that are remote. The illusion of distance may hence be produced by decreasing the brightness of the object viewed, by changing the nature of the medium, or by increasing the contrast between light and shade.

III. Near objects that are almost aligned with those which are remote, often partly cover them. Covering objects are judged nearer than those covered.

IV. Familiarity with the dimensions of known objects when near enables us to compare them when remote, and thereby judge their relative distance.

$V$. By moving from one stand-point to another, and comparing the new view with what is retained in memory of the previous one, parallax of motion thus contributes to the formation of a judgment of both distance and form.

All of these elements may be imitated in pictures, except the last. In the examination of ordinary stereographs they are combined with the important element of binocular perspective, and to such an extent that it is impossible to know just how much we are indebted to binocular perspective for the illusion of apparent relief. Skeleton diagrams, properly constructed, are hence the only means of studying stereoscopic vision, if this term be taken as a synonyme of binocular vision. If Mr. Pratt will try his method with an outline drawing, it will fail.

In regarding an ordinary painting, binocular vision is often a hinderance, rather than an aid, in appreciating perspective. It is at least important to cut off from view the objects surrounding the picture, which we involuntarily take into comparison with it. In the application of geometry to perspective, a single point of view (station-point) is always assumed, and in examining the result the observer should place a single eye as nearly as possible at the same stationpoint to attain the best perspective illusion. The other eye must be closed, if he wishes to exclude the interfering element of binocular vision which will at once be unconsciously applied to the card or canvas on which the picture has been made.

It is by the observance of these precautions that $\mathrm{Mr}$. Pratt has been able to appreciate perspective in the pictures examined, but true stereoscopic vision was excluded instead of being attained by what he may have supposed to be a new method.

Brooklyn, Jan. 1, 1887.

W. LeConte Stevens.

\section{Star rays.}

Mr. Randolph will find the phenomenon of the long vertical rays or streamers proceeding from a strongly luminous point described and fully explained in my little volume entitled 'Sight,' pp. 8789. They are produced, not by reflection from the eyelashes, as he supposes, but by refraction of light passing through the meniscus of moisture between the lid and the cornea, and are therefore more distinct when the lids are brought near together. I had investigated the phenomenon and ascertained its cause before I was aware of the very brief mention of it in Daguin's 'Traité de physique,' vol. iv. p. 323.

The radiating points about a star are more difficult to explain. They are probably due to some peculiarity in the structure of the crystalline lens.

Berkeley, Cal., Dec. 25. JOSEPH LECoNTE.

\section{A German sentence.}

In your current number you give an example of a German sentence. In Teutonicity it can hardly compete with the following extract from an advertisement of a well-known periodical: "Als eines der vorzüglichsten Weihnachtsgeschenke müssen die elegant gebundenen Quartalsbände der Deutschen Rundschau herausgegeben von Julius Rodenberg Preis pro Band in elegantem, rothem Originalleinwandband mit Schwarz und Golddruck 8 Mark bezeichnet werden."

Washington, Jan. 3, $188 \%$.

N.

\section{Pleuro-pneumonia.}

It may not be worth while to call attention to two slight mistakes in the printing of my communication on p. 631 (viii. No. 204). The 'meplis' should be 'Mehlis,' the author of micrurus; and the 'U. S. fish commission' on the first line of second column should be 'U. S. entomological commission.'

Washington, D.C., Jan. 3, 1887. 